\title{
Hipócrates, Agustín y Kepler, fuentes de referencia contra la propagación en internet de las falsas noticias de salud
}

\section{Hippocrates, Augustine and Kepler, sources of reference against the spread of fake health news on the internet}

\author{
Carlos Cachán-Alcoleaa, Juan Pablo Mateos Abarcab, Antonio Vaquerizo Mariscala \\ a Facultad de Comunicación y Artes, Universidad Nebrija, España \\ b Facultad de Ciencias de la Comunicación, Universidad Complutense de Madrid, España
}

\section{Resumen}

Noticias falsas, afirmaciones engañosas, bulos, medias verdades, mentiras... Para vencer al virus de la desconfianza, alimentado por las falsas noticias de salud que circulan por internet -y más en tiempos de coronavirus-, la receta es acudir a los expertos, como son los científicos y los profesores, actividad que comparten Hipócrates, Agustín de Hipona y Kepler. Desde nuestro punto de vista, los tres están entre esas fuentes de prestigio para informarse bien de los acontecimientos y descubrir las falsas noticias (fake news) de las que, por regla general, la gente se entera por un tuit o una notificación que salta de pronto en la pantalla de su smartphone. A nuestro entender, las bases de la información veraz no las ofrece la tecnología como un fin en sí mismo. Es el espíritu de las profundas convicciones lo que define la objetividad subyacente en los hechos comprobables.

Palabras clave: Hipócrates; Agustín de Hipona; Kepler; fuentes de referencia; noticias falsas; coronavirus; internet; salud.

\begin{abstract}
Fake news, misleading claims, hoaxes, half-truths, lies... In order to battle the virus of distrust, fed by fake health news circulating on the internet - particularly in times of coronavirus - the solution is to resort to experts such as scientists and professors, activities shared by Hippocrates, Augustine of Hippo and Kepler. From our point of view, the three are amongst those highly regarded sources for becoming well informed of events and uncovering fake news which, as a general rule, is spread by a tweet or a notification which pops up on one's smartphone. In our opinion, the basis of truthful information is not offered by technology as an end in itself. It is the spirit of deep convictions that defines the objectivity underlying the verifiable facts.
\end{abstract}

Key words: Hippocrates; Augustine of Hippo; Kepler; sources of reference; fake news; coronavirus; internet; health. 


\section{Introducción}

Respetaré a mi maestro de medicina. Comunicaré los preceptos, las lecciones orales y el resto de la enseñanza a los discípulos por un compromiso y un juramento según la ley médica. Si cumplo este juramento sin infringirlo, seré honrado siempre por los hombres y por la más remota posteridad (Mansilla et al., 2017; Comissió de bioética, 2018).

A veces deseaba sinceramente consultar esos libros ayudado de algún hombre docto que los conociera bien para así poder ver su opinión sobre ellos, y así poder juzgar realmente por mí mismo (Agustín, 1986, p.82).

Construyamos naves y velas adecuadamente para el aire de los cielos. Porque entonces también habrá gente que no se arredre ante la desierta soledad del espacio (Caspar, 2003, p.247).

A I igual que el coronavirus, las noticias falsas (fake news) no son fáciles de detectar. Son un fenómeno complejo de cuantificar. En primer lugar, porque ni siquiera es sencillo definirlo. Una cosa es reconocer, siempre que no ciegue la ideología, la mentira burda (historias inventadas, citas falsas, datos erróneos, suplantación de identidad a través de herramientas tecnológicas). Pero más acá de esos casos -y hay mucho terreno en este más acá-, las fronteras son movedizas. Los límites entre el engaño, el sesgo ideológico de una noticia o la pura opinión no siempre son claros (Rodríguez-Borlado, 2020).

La dificultad para la verdad no es una novedad en la historia humana. La novedad es el canal de transmisión: internet y redes sociales digitales. El arte de mentir ya no es patrimonio de unos pocos intoxicadores analógicos. Ahora pertenece a los que, a través de las tecnologías de la información y la comunicación, colocan "afirmaciones falsas 0 incompletas, bien aderezadas y debidamente difundidas por las redes" (Martínez, 2020).

El Colegio de Médicos de Barcelona (COMB) organizó el 4 de abril de 2019 la Jornada WMA1: ¿Cómo combatir las "fake news" de salud en la red? En dicha jornada, se presentó el vídeo de inicio de la campaña \#SalutSenseTrampes y \#SaludSinBulos, donde médicos y personalidades de la cultura, la comunicación y el deporte transmitían a los ciudadanos que ante la gran cantidad de información de salud que hay en internet, es "indispensable tener precaución y aplicar el sentido común y el espíritu crítico a la hora de seleccionar contenidos". El vídeo del COMB reconoce que internet

\footnotetext{
1 Web Médica Acreditada (WMA) es un servicio del Colegio de Médicos de Barcelona (COMB) de acreditación de webs médicas que otorga un sello de calidad a los contenidos de confianza.
}

contiene muchos contenidos útiles y de calidad. Pero también mucha desinformación y falsas noticias, que pueden provocar "un riesgo grave para la salud" (Organización Médica Colegial, 2019). A través del vídeo se recomienda: identificar quién hay detrás de una información de salud; desconfiar de promesas de curación milagrosa y de falsos rumores sin evidencia científica y consultar a un profesional sanitario antes de tomar alguna decisión sería que afecte a la salud. Según la web Lab Test Online ${ }^{2}$, una de cada tres noticias falsas en internet está relacionada con la salud, el $75 \%$ de los videos sobre cáncer en YouTube contiene información falsa y un $60 \%$ de la población en España usa internet para informarse sobre su salud (LabTestsOnline, 2019).

Sí, en internet y en las redes sociales hay información veraz y contrastada; pero la balanza está desequilibrada a favor de las falsas noticias. Más en tiempos de coronavirus. He aquí unas cuantas que circulan por internet y WhatsApp, desveladas en la edición impresa de El Mundo, entre el 29 de marzo y el 19 de abril: "el alcohol protege frente al virus"; "el sol y las temperaturas superiores a $25^{\circ}$ te protegen frente al coronavirus"; "respirar vapor de agua caliente reduce 0 mata al coronavirus"; "los mosquitos pueden contagiar la Covid-19"; "contener la respiración durante al menos 10 segundos sin toser o sentir molestias es señal de que estamos libre de la Covid-19"; "el coronavirus viaja por redes móviles y ondas de radio" (El Mundo, 2020).

\section{Corpus}

El periodista y escritor alemán Peter Seewald le hizo notar a Josep Ratzinger que Aldus Huxley, en su novela Un mundo feliz, escribió que la falsedad o la ausencia de verdad sería el aspecto característico de la sociedad moderna. Otro escritor inglés, el periodista George Orwell, afinó aún más al predecir la creación de una "realidad paralela" en su novela 1984.

¿El ser humano es capaz de la verdad? El teólogo Ratzinger -elegido Papa el 19 de abril de 2005 con el nombre de Benedicto XVI (2010)- le dijo a Seewald que es capaz. "La convicción de que existe una verdad que debe ser buscada y reconocida es un antídoto

\footnotetext{
2 Web fruto de la colaboración entre las sociedades científicas que representan a los laboratorios clínicos. Para garantizar que sea aceptada como una fuente fiable de información médica, nos adherimos a los principios asumidos por la Health On the Net Foundation, organización sin ánimo de lucro que intenta "guiar a las personas o a los usuarios no profesionales de la sanidad, a obtener información médica online útil y fiable". La versión española nace de la colaboración entre Lab Tests Online en EEUU (AACC), la Asociación Europea de Fabricantes de Material de Diagnóstico (EDMA), la Sociedad Española de Bioquímica Clínica y Patología Molecular (SEQC) y la Federación Española de Empresas de Tecnología Sanitaria (FENIN): https://labtestsonline.es/acerca-de-esta-web
} 
contra la arbitrariedad de quienes pretenden imponer al resto sus opiniones, sus deseos, su voluntad de poder" (Meseguer, 2018), en muchas ocasiones usando internet como vía de propagación.

El antídoto a la mentira es de sobra conocido: consultar a los expertos y acudir a las fuentes de referencia. La influencia va más allá de la mera difusión de sus escritos, ya que gozan de alta estima y credibilidad colectiva, y contribuyen poderosamente a la creación de estados de opinión evitando los estereotipos y los prejuicios acríticos. Porque los manipuladores y los embusteros "conviven mal con los expertos y con los datos que contradicen sus intereses" (Naím, 2020).

Nosotros lo hemos hecho. Hemos conversado con el médico griego Hipócrates (460 a. C.-370 a. C.), el filósofo romano Agustín de Hipona (354-430) y el matemático y astrónomo alemán Kepler (1571-1630). Los tres están entre las máximas figuras de la historia de la civilización occidental. Los tres buscaron la sabiduría, ese conocimiento de los primeros principios y de las primeras causas de sus respectivas disciplinas en relación con ellos, "a través de un esfuerzo estable de reflexión" (Gilson, 2015, p.31), para encontrar la verdad sobre la existencia humana. Para los periodistas y los comunicadores de salud, los tres son hoy fuentes fiables de verificación de un conjunto de valores constantes que han hecho grande a la humanidad. Aportan la serenidad que ayuda a entender el mundo, a percibir cómo son las cosas (Hochschild, 2016). Como Hannah Arendt, nosotros queremos comprender. $Y$ deseamos que también nuestros lectores comprendan.

\section{Buscadores de la verdad}

Hipócrates, Agustín y Kepler eran observadores de la realidad de sus respectivos tiempos, estudiosos de los conocimientos científicos acumulados a lo largo de la historia e investigadores de los acontecimientos pasados y presentes, así como de los cambios, los desafíos derivados de los nuevos descubrimientos. Buscaban para dar respuestas o soluciones, con la verdad o la veracidad como premisa. Eran sabedores de la dificultad de encontrar la verdad y el gozo (gaudium de veritatem) que produce dar con ella y transmitírsela a los demás.

La honestidad intelectual de los tres era incompatible con la propagación de la mentira o la falsedad, tenían que decir la verdad y dar una información cierta sobre los acontecimientos. Combatían las falsas noticias científicas presentando bien los hechos, en su contexto, y analizando con rectitud las novedades. Sus desacuerdos y críticas las expresaban -de palabra o por escrito- con respeto hacia la persona. Profundizaban, ofrecían datos, tras muchas horas, meses, incluso años de estudio. Los tres vivían en un mundo analógico, aunque no por ello desconectado, aislado, de compartimentos estancos. No era, como el de hoy, un mundo virtual, digital "de las vidas precarias que nos consumen el tiempo, el de la falta de compromisos reales, el de las apariencias" (Urraca, 2019).

Hipócrates, Agustín y Kepler eran eruditos, aunque no lo sabían todo, no estaban en posesión del conocimiento universal. Y lo eran porque conocían prácticamente todo lo que, en sus respectivos tiempos, podía conocerse en su campo; percatados de su propia ignorancia, trabajaban muy duro para reducirla. "Un verdadero erudito es en esencia un hombre cuya vida intelectual es parte de su vida moral; en otras palabras, un erudito es un hombre que ha decidido, de una vez por todas, aplicar las exigencias de su conciencia moral a su vida intelectual" (Gilson, 2015, p. 19-20).

\section{No hacer daño}

"Ante todo, no hacer daño" (Primum non nocere). Máxima profesional y ética que exigía y exige Hipócrates a los médicos. La sentencia hipocrática, elemental para la medicina (Basset, 2009), es la razón de ser de Hipócrates, que recurre al bisturí para luchar contra las afecciones, propone el empleo de plantas medicinales y recomienda una alimentación sana y equilibrada. A la medicina practicada por él y su escuela le debemos la realización de observaciones minuciosas de los síntomas y la importancia del historial clínico de los enfermos (Ruiza, Fernández y Tamaro, 2004). Padre de la medicina, pionero de la ciencia médica, Hipócrates ejerció su profesión en el norte de Grecia y murió en Larisa, entorno a los 80 años. Una de las luminarias griegas, según Platón y Aristóteles. Fundador de la medicina fisiológica -basada en el funcionamiento del organismo-, que reemplazó a las prácticas curativas de carácter mágico.

Las escuelas médicas de Asia Menor y la Magna Grecia (Sicilia y sur de Italia) del siglo VI a. C. pretendían una sistematización científica y alejarse lo más posible de la curación mágica de los santuarios vinculados al dios de la medicina Asclepio (Esculapio para los romanos). Los portallaves y los piróforos, "mitad sacerdotes y mitad enfermeros" (Montanelli, 1961, p. 231) eran sus representantes en la tierra. No sabemos con precisión en qué consistían las curas. Pero sí que utilizaban las aguas termales, pues la región abundaba en manantiales, y la sugestión mediante exorcismos y espectaculares ceremonias. Los sacerdotes de Asclepios monopolizaron 
la medicina griega hasta el siglo $\mathrm{V}$, cuando empezó la medicina basada en bases racionales.

Los encargados de la Biblioteca de Alejandría nominaron "hipocráticos" a un conjunto de textos anónimos de contenido médico. Es el Corpus Hippocraticum: una colección de más de 50 tratados sobre medicina (general, anatomía, ginecología, dietética, deontología, obstetricia, pediatría, cirugía y oftalmología). No hay evidencia de que los tratados más importantes fueran de Hipócrates (El pronóstico, Sobre la ciencia médica, Sobre la naturaleza del hombre, Sobre la medicina antigua, Sobre la dieta), aunque muchos se redactaron en su época (Cano, 2006, p. 14).

Si es evidente que Hipócrates formuló la diagnosis. El diagnóstico procede de la observación y exploración directa -in situ- del cuerpo del enfermo: mirar, tocar, escuchar la respiración, toses y ventosidades, así como la exploración olfativa de la piel, la boca, la orina y las heces. De esa observación y las manifestaciones de su enfermedad, extrae conclusiones.

Hipócrates fue pionero en vincular salud, medio ambiente y alimentación, tiene en cuenta el contexto geográfico del paciente (dónde vive, climatología), alimentación, agua, qué vida hace, hábitos, edad o sexo. Subraya la importancia de la comunicación y el diálogo con el paciente para establecer el diagnóstico. Para él, la medicina está al servicio de "la ciudad y del ser humano, y no el ser humano al servicio de la ciencia; el médico ha de amar su ciencia, pero también a la humanidad" (Cano, 2006, p.14). Su buena reputación es el resultado de una honesta práctica de la medicina, su respeto por la persona, y no prometer al paciente lo imposible. Hipócrates, según queda reflejado en el juramento que lleva su nombre, subrayó la importancia de la educación, de la formación, los descubrimientos y la obligación de enseñárselos a sus compañeros de profesión y a los "discípulos juramentados para seguir las leyes de la medicina" (Salvat, 2004, p.471).

Hipócrates humanizó la medicina y su ética se refleja en el juramento hipocrático: texto fundamental de la medicina durante más de 1500 años. La medicina de Hipócrates refleja "el progreso liberador que tendía a aumentar la soberanía del hombre, cuyo destino estaba sellado antes de su nacimiento, y a restringir, por tanto, la arbitrariedad de los dioses" (Benoist-Méchin, 1984, p.31), empeñados en cortar la emancipación del hombre. Desde el punto de vista científico y didáctico, fue el primero que separó la medicina de la religión y la convirtió en ciencia autónoma. Gracias a Hipócrates, la profesión de médico, hasta ese momento imbuida de charlatanería, empezó a valorarse. Los médicos, antes de empezar a ejercer, debían prestar obligatoriamente un juramento, que les comprometía a ejercer según ciencia y conciencia y a guardar una actitud mesurada que inspirase confianza al paciente. Desde entonces, los médicos empezaron a celebrar congresos donde cada uno aportaba la contribución de sus propias experiencias y descubrimientos.

El prestigio profesional y la fama de Hipócrates fue enorme. Fue reconocido en todo el mundo, desde Macedonia hasta Persia. En el año 430 a. C., el gobierno de Atenas le invitó para que estudiara el modo de atajar una epidemia de tifus petequial, aunque la historia no ha dejado testimonios de "qué curas prescribió ni qué resultados obtuvo" (Montanelli, 1961, p. 31).

\section{Falsos argumentos}

El filósofo y profesor de literatura latina y de retórica, Agustín de Hipona, no hizo el juramento Hipocrático, pero sí practicó, y sigue haciéndolo, la comunicación y el diálogo con sus interlocutores para advertirles de que se cuidaran de los "falsos argumentos" y enseñarles a distinguir "entre los hechos verdaderos y las falsas teorías" (Agustín, 2019, p. 272). Sabía que si preguntásemos a todos los seres humanos si prefieren la verdad a la mentira, todos a una responderían que prefieren la verdad. Esta afirmación ha sido, es y será, una constante universal del ser humano, sin importar que sea analógico o virtual el mundo en el que viva. La verdad y la mentira acompañan al hombre desde su aparición en la tierra. Lo que pasa es que, "quizás ahora [señala el director de cine italiano Matteo Garrone ${ }^{3}$ l la mentira juega un papel más destacado por culpa de internet" (Martínez, 2020). Según Garrone, la verdad importa más que la realidad.

Conservemos nuestras mentes abiertas a toda la verdad,
sea vieja o nueva. Sometámonos alegremente a ella,
cualquiera que sea la época o la dirección de donde
venga. Siempre prestos a ceder ante la verdad, resueltos
a adherirnos a ella, y ella nos ahorrará la pesadumbre
de ceder ante cualquier otra persona o cosa. La verdad
nos hace libres, la sumisión a la verdad, grandes (Gilson,
2015 , p. 28).

Agustín es un buen referente de las palabras dirigidas por el filósofo e historiador Gilson a los miembros de la Escuela de Posgrado en Artes y Letras de la Universidad de Harvard.

\footnotetext{
3 Director de la película Pinocchio, protagonizada por el oscarizado Roberto Benigni, como Geppetto, y Federico lelapi, como Pinocchio, y presentada en el Festival de Berlín 2020.
} 


\section{Bien informado}

Profesor de retórica, experto en oratoria y autor de Confesiones -escrito hace 1.633 años, pero que sigue "sin envejecer, y no envejecerá, porque es verdad", afirma Urbina en su Excusa a su traducción libre-. Agustín no estudió la medicina de Hipócrates, pero se mantuvo bien informado al respecto. Su biblioteca, según el historiador Henry Chadwick, incluía libros de texto clínicos y estudió la mejor guía de ginecología. Como obispo de Hipona, fuente de referencia dogmática y doctrinal, "pensó que tenía el deber y el derecho de decirles a los cristianos casados lo que podían, o no podían hacer en la cama durante la cuaresma" (Chadwick, 2001, p.185).

Agustín fue uno de los pensadores más influyentes e "importantes del conjunto del pensamiento occidental" (Ponsatí-Murlà, 2015, p. 13), era consciente de su ignorancia en algunos aspectos relacionados con la comida y la bebida. Conocía que hay que tomar alimentos para satisfacer necesidades y tomarlos como si fueran medicinas. Sabía que la salud del cuerpo y el deleite deseado por la voluntad no son la misma cosa, porque lo que es suficiente para la salud es poco para el placer:

Muchas veces [admite en el libro $X, 31$ de sus Confesiones] no sabemos si el cuidado necesario del cuerpo pide lo que se le da o es el deleitoso engaño del apetito el que pide que se le atienda. Ante esta incertidumbre el alma infeliz se alegra y se sirve de ella para preparar la defensa de su excusa, gozándose de no ver con claridad lo que le basta para el mantenimiento de la salud y así encubrir con tal pretexto la satisfacción del deleite (Agustín, 2019, p.292).

Tal complejidad le lleva a plasmar por escrito sus dudas, porque su criterio sobre estas cosas no es firme todavía. El "primer navegante y buceador de los mundos oscuros del yo interior, de la conciencia", donde el hombre encuentra la "realidad más íntima que su mismo yo" -escribe Rodríguez de Santidrián en su prólogo a Confesiones- está perplejo, pues su criterio sobre este asunto no es todavía lo suficientemente seguro.

\section{Universo físico}

La astrología estaba muy arraigada entre los romanos tardíos por la necesidad de los astrólogos de sus observaciones empíricas para hacer horóscopos correctamente y predecir con mucha antelación un eclipse de sol. Agustín había comprobado ciertos los cálculos astronómicos. Su interés por el universo físico evidencia una constante del ser humano: los horóscopos de los astrólogos de los siglos IV y $\mathrm{V}$ al igual que los almanaques de los astrónomos en los siglos XVI y
XVII así lo atestiguan. Kepler, el padre de la moderna astronomía, escribió en su almanaque de 1604:

En verdad puedo decir que cuando con el pensamiento recorro el bello orden con que lo uno deriva de una cosa y deviene en otra, es como si leyera una máxima divina escrita directamente en el mundo no con palabras, sino con objetos esenciales, que reza así: Hunde aquí tu entendimiento para comprender estos asuntos (Caspar, 2003, p.5).

Kepler vivió en una época de profusión de textos astrológicos, alquímicos, cabalísticos, mágicos y pseudomísticos. En su tiempo -como en los de Hipócrates y Agustín- era grande la creencia en el influjo de los astros sobre los acontecimientos futuros. Calendarista reputado y consciente de la influencia de sus almanaques (el primero lo publicó en 1595), rechazaba las predicciones al uso considerándolas "supersticiones monstruosas" o un "sortilegio juego de monos".

Como autor de pronósticos, Kepler tenía en cuenta que debían evitar la búsqueda de fama e infundir miedo. No le disgusta realizar predicciones, pero nos advierte que no hay que confiar en los vaticinios. Los escribe como vehículo para transmitir su opinión a la gente que no entiende nada sobre ciencia y para ganarse la vida sabiendo que con ello podía perder crédito científico entre los entendidos, entre la gente instruida (Caspar, 2003, p.76-78). Como Agustín, Kepler siempre quiso comprender las cosas que conocía. Como Agustín e Hipócrates, deseaba ser útil a todos los seres humanos. Sus descubrimientos (confirmó las teorías de Copérnico, leyes del movimiento planetario, óptica moderna, reforma del sistema de pesos y medidas...) los dejó escritos -para el presente y para la posteridad- en libros sobre el universo donde se refleja la precisión de sus investigaciones científicas.

No nos cabe duda de que a Hipócrates le hubiera gustado ser el médico de cabecera de Kepler y curarle de sus tantísimas enfermedades miopía, poliopía monocular, que le hacía percibir las imágenes múltiples; accesos febriles, males estomacales y biliares (cualquier error en su dieta le provocaba un ataque); ulceraciones y erupciones cutáneas en diversas partes del cuerpo, sobre todo en la espalda. También quisiera serlo para desaconsejarle sus malos hábitos culinarios (roer huesos, comer pan seco, alimentos amargos y picantes) y animarle a que se bañara con más frecuencia e hiciera abluciones.

Sabedor de que sus descubrimientos científicos en matemáticas y astronomía le habían convertido en un referente de la ciencia celeste, no tuvo inconveniente alguno en reconocer abiertamente y complacido los 
méritos de otros en cuanto se encontraba con ellos. Jamás despreció o encubrió la sabiduría ajena cuando le faltaba la propia. Fue una fuente de referencia activa y colaborativa para los maestros de la ciencia que buscan lo que se percibe con los sentidos y lo que se conoce a través del espíritu. Y les recuerda que la ciencia no constituye una finalidad en sí misma, porque el fin de un investigador es el conocimiento de la verdad: "La verdad y sólo la verdad es la luz por la que él desea transitar" (Casper, 2003, p. 476). Y el conocimiento de la verdad Kepler lo persiguió en todas sus actividades: matemático, astrónomo, físico, lógico y metafísico. Igual que el filósofo Agustín. Igual que el médico Hipócrates.

\section{Discusión y Conclusión}

La COVID-19, enfermedad provocada por el coronavirus de Wuhan, es un buen ejemplo demostrativo de que los ciudadanos del mundo entero, dado su carácter de pandemia, quieren enterarse de lo que está pasando para contrastar sus experiencias con las ajenas. $Y$ al cotejar lo que les sucede con lo que les está pasando a otros, o les ocurrió en el pasado, deducir un haz de hechos y esperanzas para el futuro.

Hipócrates, Agustín y Kepler no siempre fueron testigos directos del acontecimiento. Su ausencia no les invalida para transmitir lo acaecido, pues piden el testimonio a quienes han sido protagonistas, testigos oculares o recibido la información de fuentes primarias. Para reforzar la veracidad, investigan "cuidadosamente todo lo sucedido desde el principio" y escriben "una exposición ordenada", para que los receptores de su época y los del futuro lleguen a "comprender la autenticidad" de lo sucedido (Lucas, 1998, p.1.296). Hipócrates, Agustín y Kepler practicaron en vida, y ahora con su presencia virtual, la honradez intelectual y el respeto escrupuloso de la verdad, enseñan y difunden resultados a sus contemporáneos y a las generaciones futuras (también a la nuestra), convencidos de que enseñar es la razón de su maestría.

Los tres acumulan conocimiento de la realidad, como fruto sabroso de su largo esfuerzo, y practican el amor a la verdad. No la defienden por ser vieja o nueva: ni todo lo viejo es verdad, ni todo lo nuevo lo es. "Una verdad nueva [dice Gilson] puede y debe reemplazar viejos errores" (Gilson, 2015, p.27). Ni todo lo que han dicho y escrito Hipócrates, Agustín o Kepler es verdadero simplemente porque lo han afirmado ellos, referentes de la medicina, la filosofía de la historia y las matemáticas. Pero sería ingenuo afirmar que es falso todo lo que dicen considerando los avances de la medicina, la geopolítica, la astrología.

Noticias falsas y bulos sobre el coronavirus se transmiten a gran velocidad en internet provocando desconfianza en los mensajeros mediáticos. La desinformación puede movilizarse en un doble sentido: a) rebotando sin más el falso mensaje a otras personas; b) llevando a contrastarla y verificarla consultando a expertos. Es entonces cuando Hipócrates, Agustín y Kepler se convierten en focos de luz que iluminan el camino -real o virtual- hacia el conocimiento verdadero y se alzan como barreras humanas de las fake news que circula por internet.

Hipócrates, Agustín y Kepler siguen vivos entre los que tienen ansias de saber, respeto por la grandeza espiritual y la ética. Sin duda, el avance del conocimiento científico ha revelado errores en algunas de sus ideas. No obstante, los tres continúan hablando a los hombres y mujeres del siglo XXI -y más en tiempos de coronavirusde la verdad para vencer a las noticias falsas de salud.

Agradecimientos

Profesor Daniel Catalán-Matamoros (UC3M).

\section{Referencias Bibliográficas}

San Agustín. (1986). Las Confesiones (traducción libre en versión actualizada de Pedro Antonio Urbina), $7^{\text {a }}$ edición. Madrid: Ediciones Palabra.

San Agustín. (2019). Confesiones (prólogo, traducción y notas de Pedro Rodríguez de Santidrián), reimpresión. Madrid: Alianza Editorial.

Basset, L. (2009). Hipócrates. El País, 11 de noviembre de 2009. Recuperado de: https:// elpais.com/internacional/2009/11/11/del_alfiler_al_ elefante/1257922869_125792.html. Consultado: 20 enero de 2020.

Benoist-Méchin, J. (1982). Alejandro Magno. Barcelona: Luis de Caralt Editor.

Benedicto XVI (2010). Luz del mundo. Una conversación con Peter Seewald. Madrid: Herder. Madrid. Recuperado de: http://img89.xooimage.com/ files/f/e/4/luz-del-mundo-lib...icto-xvi-37b8cab.pdf

Cano, J. (2006). Hipócrates, el padre de la medicina. Historia National Geographic, 32, 13-16.

Caspar, M. (2003). Johannes Kepler. Madrid: Acento Editorial.

Comissió de bioética. (2018). Jurament Hipocrátic. Hospital Universitari San Joan Reus. Recuperado 
de:http://www.hospitalsantjoan.cat/wp-content/ uploads/2018/07/Juramento_HIPOCRATICO.pdf

Chadwick, H. (2001). Agustín. Madrid, España: Ediciones Cristiandad.

El Mundo. (2020). Salud. El Mundo, 29 de marzo, 5, 12 y 19 de abril.

Gilson, E. (2015). El amor a la sabiduría. (presentación y notas de Rafael Tomás Caldera). Madrid: Ediciones Rialp.

Hochschild, A. (2016). Anger, mourning and the American rigth, Spiked, 29 de noviembre de 2016. Recuperado de: https://www.spiked-online. com/2016/11/29/anger-mourning-and-the-americanright/ Consultado: 1 de febrero de 2020.

Lab Tests online (2019). 'Fake news': noticias falsas sobre salud en Internet. Labtestsonline, 24 de abril de 2019. Recuperado de: https://labtestsonline. es/news/fake-news-noticias-falsas-sobre-salud-eninternet Consultado: 27 de marzo de 2020.

Lucas. (1998). Evangelio según san Lucas. En La Biblia cultural. Madrid: Ediciones SM.

Mansilla, A., Rivera, A., y Romero, F. (2017). Libro sobre Neurofisiología Humana. Facultad de Medicina. UNAM. Juramento Hipocrático. Recuperado de: http:// www.facmed.unam.mx/Libro-NeuroFisio/Personas/ Hipocrates/Hipocrates.html

Martínez, L. (2020). Benigni y Garrone: "La mentira es un tema marginal en Pinocho". El Mundo, 24 de febrero de 2020. Recuperado de: https://www. elmundo.es/cultura/cine/2020/02/24/5e52c69d21efa 09d4e8b462f.html

Martínez, J. (2020). Las cuitas de la verdad. ABC, 6 de marzo de 2020, p.3.

Meseguer, J. (2018). Pensar en una era de corrección política. Aceprensa, 26 de septiembre de 2018. Recuperado de: https://www.aceprensa.com/politica/ pensar-en-una-era-de-correccion-political

Montanelli, I. (1961). Historia de los griegos. Barcelona: Mondadori.

Naím, M. (2020). Todos somos vecinos. El País, 15 de marzo, p.10.

Organización Médica Colegial (2019). El COMB anima a los ciudadanos a ser críticos con la información en las redes sobre salud. Médicosypacientes. com, 4-4-2019. Recuperado de: http://www. medicosypacientes.com/articulo/el-comb-anima-losciudadanos-ser-criticos-con-la-informacion-en-lasredes-sobre-salud.

Ponsatí-Murlà, O. (2015). San Agustín. Barcelona: RBA.

Rodríguez-Borlado, F. (2020). Luchas contra la desinformación sin el control de un "gran hermano". Aceprensa, 17 de enero de 2020. Recuperado de: https://www.aceprensa.com/sociedad/ luchar-contra-la-desinformacion-sin-el-control-de-ungran-hermano/. Consultado: 1 de marzo de 2020.

Ruiza, M., Fernández, T., y Tamaro, E. (2004). Biografía de Hipócrates de Cros. Biografías y Vidas. La enciclopedia biográfica en línea. Barcelona. Recuperado de: http://www.biografiasyvidas.com/ biografia/h/hipocrates.htm Consultado: 1 de marzo de 2020.

Salvat (2004). Historia Universal. Grecia II (Francisco Navarro, dirección editorial, y María Teresa Llistosella, jefe de Redacción). Madrid: Salvat Editores.

Urraca, S. (2019). El silbato. El País, 24 de agosto de 2019. Recuperado de: https://elpais.com/ elpais/2019/08/16/ideas/1565954046_138076.html. Consultado: 25 de agosto de 2019. 